\title{
The digital commercialisation of US politics - 2020 and beyond
}

\section{Jeff Chester}

Center for Digital Democracy, Washington, DC, United States, jeff@democraticmedia.org

\section{Kathryn C. Montgomery}

School of Communication, American University, Washington, DC, United States, kcm@american.edu

Published on 31 Dec 2019 | DOI: 10.14763/2019.4.1443

\begin{abstract}
The same micro-targeted programmatic advertising that has become central to the digital media and marketing ecosystem has now migrated into election campaigns in the US and elsewhere, raising a host of issues around privacy, discrimination, and manipulation. This paper examines the digital strategies and technologies of today's political campaigns, explaining how they will be deployed in the upcoming 2020 election cycle, and assessing regulatory and policy responses - both enacted and proposed - for increasing transparency and accountability in digital politics.
\end{abstract}

Keywords: Advertising, Elections, Micro-targeting, Privacy

\section{Article information}

Received: 12 Jul 2019 Reviewed: 06 Nov 2019 Published: 31 Dec 2019

Licence: Creative Commons Attribution 3.0 Germany

Competing interests: The author has declared that no competing interests exist that have influenced the text.

URL: http://policyreview.info/articles/analysis/digital-commercialisation-us-politics-2020-and-beyond

Citation: Chester, J. \& Montgomery, K. C. (2019). The digital commercialisation of US politics - 2020 and beyond. Internet Policy Review, 8(4). DOI: 10.14763/2019.4.1443

This paper is part of Data-driven elections, a special issue of Internet Policy Review guestedited by Colin J. Bennett and David Lyon.

In March 2018, The New York Times and The Guardian/Observer broke an explosive story that Cambridge Analytica, a British data firm, had harvested more than 50 million Facebook profiles and used them to engage in psychometric targeting during the 2016 US presidential election (Rosenberg, Confessore, \& Cadwalladr, 2018). The scandal erupted amid ongoing concerns over Russian use of social media to interfere in the electoral process. The new revelations triggered a spate of congressional hearings and cast a spotlight on the role of digital marketing and "big data" in elections and campaigns. The controversy also generated greater scrutiny of some of the most problematic tech industry practices - including the role of algorithms on social media platforms in spreading false, hateful, and divisive content, and the use of digital micro-targeting 
techniques for "voter suppression" efforts (Green \& Issenberg; 2016; Howard, Woolley, \& Calo, 2018). In the wake of these cascading events, policymakers, journalists, and civil society groups have called for new laws and regulations to ensure transparency and accountability in online political advertising.

Twitter and Google, driven by growing concern that they will be regulated for their political advertising practices, fearful of being found in violation of the General Data Protection Regulation (GDPR) in the European Union, and cognisant of their own culpability in recent electoral controversies, have each made significant changes in their political advertising policies (Dorsey, 2019; Spencer, 2019). Despite a great deal of public hand wringing, on the other hand, US federal policymakers have failed to institute any effective remedies even though several states have enacted legislation designed to ensure greater transparency for digital political ads (California Clean Money Campaign, 2019; Garrahan, 2018). These recent legislative and regulatory initiatives in the US are narrow in scope and focused primarily on policy approaches to political advertising in more traditional media, failing to hold the tech giants accountable for their deleterious big data practices.

On the eve of the next presidential election in 2020, the pace of innovation in digital marketing continues unabated, along with its further expansion into US electoral politics. These trends were clearly evident in the 2018 election, which, according to Kantar Media, were "the most lucrative midterms in history", with $\$ 5.25$ billion USD spent for ads on local broadcast cable TV, and digital - outspending even the 2016 presidential election. Digital ad spending "quadrupled from 2014" to \$950 million USD for ads that primarily ran on Facebook and Google (Axios, 2018; Lynch, 2018). In the upcoming 2020 election, experts are forecasting overall spending on political ads will be $\$ 6$ billion USD, with an "expected $\$ 1.6$ billion to be devoted to digital video... more than double 2018 digital video spending" (Perrin, 2019). Kantar (2019), meanwhile, estimates the portion spent for digital media will be $\$ 1.2$ billion USD in the 20192020 election cycle.

In two earlier papers, we documented a number of digital practices deployed during the 2016 elections, which were emblematic of how big data systems, strategies and techniques were shaping contemporary political practice (Chester \& Montgomery, 2017, 2018). Our work is part of a growing body of interdisciplinary scholarship on the role of data and digital technologies in politics and elections. Various terms have been used to describe and explain these practices from computational politics to political micro-targeting to data-driven elections (Bodó, Helberger, \& de Vreese, 2017; Bennett, 2016; Karpf, 2016; Kreiss, 2016; Tufekci, 2014). All of these labels highlight the increasing importance of data analytics in the operations of political parties, candidate campaigns, and issue advocacy efforts. But in our view, none adequately captures the full scope of recent changes that have taken place in contemporary politics. The same commercial digital media and marketing ecosystem that has dramatically altered how corporations engage with consumers is now transforming the ways in which campaigns engage with citizens (Chester \& Montgomery, 2017).

We have been closely tracking the growth of this marketplace for more than 25 years, in the US and abroad, monitoring and analysing key technological developments, major trends, practices and players, and assessing the impact of these systems in areas such as health, financial services, retail, and youth (Chester, 2007; Montgomery, 2007, 2015; Montgomery \& Chester, 2009; Montgomery, Chester, Grier, \& Dorfman, 2012; Montgomery, Chester, \& Kopp, 2018). CDD has worked closely with leading EU civil society and data protection NGOs to address digital marketplace issues. Our work has included providing analysis to EU-based groups to help them 
respond critically to Google's acquisition of DoubleClick in 2007 as well as Facebook's purchase of WhatsApp in 2014. Our research has also been informed by a growing body of scholarship on the role that commercial and big data forces are playing in contemporary society. For example, advocates, legal experts, and scholars have written extensively about the data and privacy concerns raised by this commercial big data digital marketing system (Agre \& Rotenberg, 1997; Bennett, 2008; Nissenbaum, 2009; Schwartz \& Solove, 2011). More recent research has focused increasingly on other, and in many ways more troubling, aspects of this system. This work has included, for example, research on the use of persuasive design (including "mass personalisation" and "dark patterns") to manage and direct human behaviours; discriminatory impacts of algorithms; and a range of manipulative practices (Calo, 2013; Gray, Kou, Battles, Hoggatt, \& Toombs, 2018; Susser, Roessler, \& Nissenbaum, 2019; Zarsky, 2019; Zuboff, 2019). As digital marketing has migrated into electoral politics, a growing number of scholars have begun to examine the implications of these problematic practices on the democratic process (Gorton, 2016; Kim et al., 2018; Kreiss \& Howard, 2010; Rubinstein, 2014; Bashyakarla et al., 2019; Tufekci, 2014).

The purpose of this paper is to serve as an "early warning system" - for policymakers, journalists, scholars, and the public - by identifying what we see as the most important industry trends and practices likely to play a role in the next major US election, and flagging some of the problems and issues raised. Our intent is not to provide a comprehensive analysis of all the tools and techniques in what is frequently called the "politech" marketplace. The recent Tactical Tech (Bashyakarla et al, 2019) publication, Personal Data: Political Persuasion, provides a highly useful compendium on this topic. Rather, we want to show how further growth and expansion of the big data digital marketplace is reshaping electoral politics in the US, introducing both candidate and issue campaigns to a system of sophisticated software applications and data-targeting tools that are rooted in the goals, values, and strategies for influencing consumer behaviours. 1 Although some of these new digitally enabled capabilities are extensions of longstanding political practices that pre-date the internet, others are a significant departure from established norms and procedures. Taken together, they are contributing to a major shift in how political campaigns conduct their operations, raising a host of troubling issues concerning privacy, security, manipulation, and discrimination. All of these developments are taking place, moreover, within a regulatory structure that is weak and largely ineffectual, posing daunting challenges to policymakers.

In the following pages, we: 1) briefly highlight five key developments in the digital marketing industry since the 2016 election that are influencing the operations of political campaigns and will likely affect the next election cycle; 2) discuss the implications of these trends and techniques for the ongoing practice of contemporary politics, with a special focus on their potential for manipulation and discrimination; 3) assess both the technology industry responses and recent policy initiatives designed to address political advertising in the US; and 4) offer our own set of recommendations for regulating political ad and data practices.

\section{THE GROWING BIG DATA COMMERCIAL AND POLITICAL MARKETING SYSTEM}

In the upcoming 2020 elections, the US is likely to witness an extremely hard-fought, underthe-radar, innovative, and in many ways disturbing set of races, not only for the White House but also for down-ballot candidates and issue groups. Political campaigns will be able to avail 
themselves of the current state-of-the-art big data systems that were used in the past two elections, along with a host of recent advances developed by commercial marketers. Several interrelated trends in the digital media and marketing industry are likely to play a particularly influential role in shaping the use of digital tools and strategies in the 2020 election. We discuss them briefly below:

Recent mergers and partnerships in the media and data industries are creating new synergies that will extend the reach and enhance the capabilities of contemporary political campaigns. In the last few years, a wave of mergers and partnerships has taken place among platforms, data brokers, advertising exchanges, ad agencies, measurement firms and companies specialising in advertising technologies (so-called "ad-tech"). This consolidation has helped fuel the unfettered growth of a powerful digital marketing ecosystem, along with an expanding spectrum of software systems, specialty firms, and techniques that are now available to political campaigns. For example, AT\&T (n.d.), as part of its acquisition of Time Warner Media, has re-launched its digital ad division, now called Xandr (n.d.). It also acquired the leading programmatic ad platform AppNexus

Leading multinational advertising agencies have made substantial acquisitions of data companies, such as the Interpublic Group (IPG) purchase of Acxiom in 2018 and the Publicis Groupe takeover of Epsilon in 2019. One of the "Big 3" consumer credit reporting companies, TransUnion (2019), bought TruSignal, a leading digital marketing firm. Such deals enable political campaigns and others to easily access more information to profile and target potential voters (Williams, 2019).

In the already highly consolidated US broadband access market, only a handful of giants provide the bulk of internet connections for consumers. The growing role of internet service providers (ISPs) in the political ad market is particularly troubling, since they are free from any net neutrality, online privacy or digital marketing rules. Acquisitions made by the telecommunications sector are further enabling ISPs and other telephony companies to monetise their highly detailed subscriber data, combining it with behavioural data about device use and content preferences, as well as geolocation. (Schiff, 2018).

Increasing sophistication in "identity resolution" technologies, which take advantage of machine learning and artificial intelligence applications, is enabling greater precision in finding and reaching individuals across all of their digital devices. The technologies used for what is known as "identity resolution" have evolved to enable marketers - and political groups - to target and "reach real people" with greater precision than ever before. Marketers are helping perfect a system that leverages and integrates, increasingly in real-time, consumer profile data with online behaviours to capture more granular profiles of individuals, including where they go, and what they do (Rapp, 2018). Facebook, Google and other major marketers are also using machine learning to power prediction-related tools on their digital ad platforms. As part of Google's recent reorganisation of its ad system (now called the "Google Marketing Platform"), the company introduced machine learning into its search advertising and YouTube businesses (Dischler, 2018; Sluis, 2018). It also uses machine learning for its "Dynamic Prospecting" system, which is connected to an "Automatic Targeting" apparatus that enables more precise tracking and targeting of individuals (Google, n.d.-a-b). Facebook (2019) is enthusiastically promoting machine learning as a fundamental advertising tool, urging advertisers to step aside and let automated systems make more ad-targeting decisions.

Political campaigns have already embraced these new technologies, even creating a special category in the industry awards for "Best Application of Artificial Intelligence or Machine 
Learning”, "Best Use of Data Analytics/Machine Learning”, and "Best Use of Programmatic Advertising" ("2019 Reed Award Winners", 2019; American Association of American Political Consultants, 2019). For example, Resonate, a digital data marketing firm, was recognised in 2018 for its "Targeting Alabama's Conservative Media Bubble", which relied on "artificial intelligence and advanced predictive modeling" to analyse in real-time "more than 15 billion page loads per day. According to Resonate, this process identified "over 240,00o voters" who were judged to be "persuadable" in a hard-fought Senate campaign (Fitzpatrick, 2018). Similar advances in data analytics for political efforts are becoming available for smaller campaigns (Echelon Insights, 2019). WPA Intelligence (2019) won a 2019 Reed Award for its data analytics platform that generated "daily predictive models, much like microtargeting advanced traditional polling. This tool was used on behalf of top statewide races to produce up to 900 million voter scores, per night, for the last two months of the campaign". Deployment of these techniques was a key influence in spending for the US midterm elections (Benes, 2018; Loredo, 2016; McCullough, 2016).

Political campaigns are taking advantage of a rapidly maturing commercial geo-spatial intelligence complex, enhancing mobile and other geotargeting strategies. Location analytics enable companies to make instantaneous associations between the signals sent and received from Wi-Fi routers, cell towers, a person's devices and specific locations, including restaurants, retail chains, airports, stadiums, and the like (Skyhook, n.d.). These enhanced location capabilities have further blurred the distinction between what people do in the "offline" physical world and their actions and behaviours online, giving marketers greater ability both to "shadow" and to reach individuals nearly anytime and anywhere.

A political "geo-behavioural" segment is now a "vertical" product offered alongside more traditional online advertising categories, including auto, leisure, entertainment and retail. "Hyperlocal" data strategies enable political campaigns to engage in more precise targeting in communities (Mothership Strategies, 2018). Political campaigns are also taking advantage of the widespread use of consumer navigation systems. Waze, the Google-owned navigational firm, operates its own ad system but also is increasingly integrated into the Google programmatic platform (Miller, 2018). For example, in the 2018 midterm election, a get-out-the-vote campaign for one trade group used voter file and Google data to identify a highly targeted segment of likely voters, and then relied on Waze to deliver banner ads with a link to an online video (carefully calibrated to work only when the app signalled the car wasn't moving). According to the political data firm that developed the campaign, it reached " 1 million unique users in advance of the election" (Weissbrot, 2019, April 10).

Political television advertising is rapidly expanding onto unregulated streaming and digital video platforms. For decades, television has been the primary medium used by political campaigns to reach voters in the US. Now the medium is in the process of a major transformation that will dramatically increase its central role in elections (IAB, n.d.-a). One of the most important developments during the past few years is the expansion of advertising and data-targeting capabilities, driven in part by the rapid adoption of streaming services (so-called "Over the Top" or "OTT") and the growth of digital video (Weissbrot, 2019, October 22). Leading OTT providers in the US are actively promoting their platform capabilities to political campaigns, making streaming video a new battleground for influencing the public. For example, a "Political Data Cloud" offered by OTT specialist Tru Optik (2019) enables "political advertisers to use both OTT and streaming audio to target specific voter groups on a local, state or national level across such factors as party affiliation, past voting behavior and issue orientation. Political data can be combined with behavioral, demographic and interest-based information, to create 
custom voter segments actionable across over 80 million US homes through leading publishers and ad tech platforms" (Lerner, 2019).

While political advertising on broadcast stations and cable television systems has long been subject to regulation by the US Federal Communications Commission, newer streaming television and digital video platforms operate outside of the regulatory system (O'Reilly, 2018). According to research firm Kantar "political advertisers will be able to air more spots on these streaming video platforms and extend the reach of their messaging-particularly to younger voters" (Lafayette, 2019). These ads will also be part of cross-device campaigns, with videos showing up in various formats on mobile devices as well.

The expanding role of digital platforms enables political campaigns to access additional sources of personal data, including TV programme viewing patterns. For example, in 2018, Altice and smart TV company Vizio launched a new partnership to take advantage of recent technologies now being deployed to deliver targeted advertising, incorporating viewer data from nearly nine million smart TV sets into "its footprint of more than 90 million households, $85 \%$ of broadband subscribers and one billion devices in the U.S." (Clancy, 2018). Vizio's Inscape (n.d.) division produces technology for smart TVs, offering what is known as "automatic content recognition" (ACR) data. According to Vizio, ACR enables what the industry calls "glass level" viewing data, using "screen level measurement to reveal what programs and ads are being watched in nearreal time", and incorporating the IP address from any video source in use (McAfee, 2019). Campaigns have demonstrated the efficacy of OTT's role. AdVictory (n.d.) modelled " 387,000 persuadable cord cutters and 1,210 persuadable cord shavers" (the latter referring to people using various forms of streaming video) to make a complex media buy in one state-wide gubernatorial race that reached 1.85 million people "across [video] inventory traditionally untouched by campaigns".

Further developments in personalisation techniques are enabling political campaigns to maximise their ability to test an expanding array of messaging elements on individual voters. Micro-targeting now involves a more complex personalisation process than merely using socalled behavioural data to target an individual. The use of personal data and other information to influence a consumer is part of an ever-evolving, orchestrated system designed to generate and then manage an individual's online media and advertising experiences. Google and Facebook, in particular, are adept at harvesting the latest innovations to advance their advertising capabilities, including data-driven personalisation techniques that generate hundreds of highly granular ad-campaign elements from a single "creative" (i.e., advertising message). These techniques are widely embraced by the digital marketing industry, and political campaigns across the political spectrum are being encouraged to expand their use for targeting voters (Meuse, 2018; Revolution Marketing, n.d.; Schuster, 2015). The practice is known by various names, including "creative versioning", "dynamic creative", and "Dynamic Creative Optimization", or DCO (Shah, 2019). Google's creative optimisation product, "Directors Mix" (formerly called "Vogon"), is integrated into the company's suite of "custom affinity audience targeting capabilities, which includes categories related to politics and many other interests". This product, it explains, is designed to "generate massively customized and targeted video ad campaigns" (Google, n.d.-c). Marketing experts say that Google now enables "DCO on an unprecedented scale", and that YouTube will be able to "harness the immense power of its data capabilities..." (Mindshare, 2017). Directors Mix can tap into Google's vast resources to help marketers influence people in various ways, making it "exceptionally adept at isolating particular users with particular interests" (Boynton, 2018). Facebook's "Dynamic Creative" can help transform a single ad into as many as " 6,250 unique combinations of title, image/video, 
text, description and call to action", available to target people on its news feed, Instagram and outside of Facebook's “Audience Network” ad system (Peterson, 2017).

\section{IMPLICATIONS FOR 2020 AND BEYOND}

We have been able to provide only a partial preview of the digital software systems and tools that are likely to be deployed in US political campaigns during 2020. It's already evident that digital strategies will figure even more centrally in the upcoming campaigns than they have in previous elections (Axelrod, Burke, \& Nam, 2019; Friedman, 2018, June 19). Many of the leading Democratic candidates, and President Trump, who has already ramped up his reelection campaign apparatus, have extensive experience and success in their use of digital technology. Brad Parscale, the campaign manager for Trump's re-election effort, explained in 2019 that "in every single metric, we're looking at being bigger, better, and 'badder' than we were in 2016," including the role that "new technologies" will play in the race (Filloux, 2019).

On the one hand, these digital tools could be harnessed to create a more active and engaged electorate, with particular potential to reach and mobilise young voters and other important demographic groups. For example, in the US 2018 midterm elections, newcomers such as Congresswoman Alexandria Ocasio-Cortez, with small budgets but armed with digital media savvy, were able to seize the power of social media, mobile video, and other digital platforms to connect with large swaths of voters largely overlooked by other candidates (Blommaert, 2019). The real-time capabilities of digital media could also facilitate more effective get-out-the-vote efforts, targeting and reaching individuals much more efficiently than in-person appeals and last-minute door-to-door canvassing (O’Keefe, 2019).

On the other hand, there is a very real danger that many of these digital techniques could undermine the democratic process. For example, in the 2016 election, personalised targeted campaign messages were used to identify very specific groups of individuals, including racial minorities and women, delivering highly charged messages designed to discourage them from voting (Green \& Issenberg, 2016). These kinds of "stealth media" disinformation efforts take advantage of "dark posts" and other affordances of social media platforms (Young et al., 2018).Though such intentional uses (or misuses) of digital marketing tools have generated substantial controversy and condemnation, there is no reason to believe they will not be used again. Campaigns will also be able to take advantage of a plethora of newer and more sophisticated targeting and message-testing tools, enhancing their ability to fine tune and deliver precise appeals to the specific individuals they seek to influence, and to reinforce the messages throughout that individual's "media journey".

But there is an even greater danger that the increasingly widespread reliance on commercial ad technology tools in the practice of politics will become routine and normalised, subverting independent and autonomous decision making, which is so essential to an informed electorate (Burkell \& Regan, 2019; Gorton, 2016). For example, so-called "dynamic creative" advertising systems are in some ways extensions of A/B testing, which has been a longstanding tool in political campaigns. However, today's digital incarnation of the practice makes it possible to test thousands of message variations, assessing how each individual responds to them, and changing the content in real time and across media in order to target and retarget specific voters. The data available for this process are extensive, granular, and intimate, incorporating personal information that extends far beyond the conventional categories, encompassing behavioural patterns, psychographic profiles, and TV viewing histories. Such techniques are inherently 
manipulative (Burkell \& Regan, 2019; Gorton, 2016; Susser, Roessler, \& Nissenbaum, 2019). The increasing use of digital video, in all of its new forms, raises similar concerns, especially when delivered to individuals through mobile and other platforms, generating huge volumes of powerful, immersive, persuasive content, and challenging the ability of journalists and scholars to review claims effectively. AI, machine learning, and other automated systems will be able to make predictions on behaviours and have an impact on public decision-making, without any mechanism for accountability. Taken together, all of these data-gathering, -analysis, and targeting tools raise the spectre of a growing political surveillance system, capable of capturing unlimited amounts of detailed and highly sensitive information on citizens and using it for a variety of purposes. The increasing predominance of the big data political apparatus could also usher in a new era of permanent campaign operations, where individuals and groups throughout the country are continually monitored, targeted, and managed.

Because all of these systems are part of the opaque and increasingly automated operations of digital commercial marketing, the techniques, strategies, and messages of the upcoming campaigns will be even less transparent than before. In the heat of a competitive political race, campaigns are not likely to publicise the full extent of their digital operations. As a consequence, journalists, civil society groups, and academics may not be able to assess them fully until after the election. Nor will it be enough to rely on documenting expenditures, because digital ads can be inexpensive, purposefully designed to work virally and aimed at garnering "free media", resulting in a proliferation of messages that evade categorisation or accountability as "paid political advertising".

Some scholars have raised doubts about the effectiveness of contemporary big data and digital marketing applications when applied to the political sphere, and the likelihood of their widespread adoption (Baldwin-Philippi, 2017). It is true we are in the early stages of development and implementation of these new tools, and it may be too early to predict how widely they will be used in electoral politics, or how effective they might be. However, the success of digital marketing worldwide in promoting brands and products in the consumer marketplace, combined with the investments and innovations that are expanding its ability to deliver highly measured impacts, suggest to us that these applications will play an important role in our political and electoral affairs. The digital marketing industry has developed an array of measurement approaches to document their impact on the behaviour of individuals and communities (Griner, 2019; IAB Europe, 2019; MMA, 2019). In the no-holds-barred environment of highly competitive electoral politics, campaigns are likely to deploy these and other tools at their disposal, without restraint. There are enough indications from the most recent uses of these technologies in the political arena to raise serious concerns, making it particularly urgent to monitor them very closely in upcoming elections.

\section{INDUSTRY AND LEGISLATIVE INITIATIVES}

The largest US technology companies have recently introduced a succession of internal policies and transparency measures aimed at ensuring greater platform responsibility during elections. In November 2019, Twitter announced it was prohibiting the "promotion of political content", explaining that it believed that "political message reach should be earned, not bought". CEO Jack Dorsey (2019) was remarkably frank in explaining why Twitter had made this decision: "Internet political ads present entirely new challenges to civic discourse: machine learningbased optimization of messaging and micro-targeting, unchecked misleading information, and deep fakes. All at increasing velocity, sophistication, and overwhelming scale”. 
That same month, Google unveiled policy changes of its own, including restricting the kinds of internal data capabilities available to political campaigns. As the company explained, "we're limiting election ads audience targeting to the following general categories: age, gender, and general location (postal code level)". Google also announced it was "clarifying" its ads policies and "adding examples to show how our policies prohibit things like 'deep fakes' (doctored and manipulated media), misleading claims about the census process, and ads or destinations making demonstrably false claims that could significantly undermine participation or trust in an electoral or democratic process" (Spencer, 2019). It remains to be seen whether such changes as Google's and Twitter's will actually alter, in any significant way, the contemporary operations of data-driven political campaigns. Some observers believe that Google's new policy will benefit the company, noting that "by taking away the ability to serve specific audiences content that is most relevant to their values and interests, Google stands to make a lot MORE money off of campaigns, as we'll have to spend more to find and reach our intended audiences" "FWIW: The Platform Self-regulation Dumpster Fire”, 2019).

Interestingly, Facebook, the tech company that has been subject to the greatest amount of public controversy over its political practices, had not, at the time of this writing, made similar changes in its political advertising policies. Though the social media giant has been widely criticised for its refusal to fact-check political ads for accuracy and fairness, it has not been willing to institute any mechanisms for intervening in the content of those ads (Ingram, 2018; Isaac, 2019; Kafka, 2019). However, Facebook did announce in 2018 that it was ending its participation in the industry-wide practice of embedding, which involved sales teams working hand-in-hand with leading political campaigns (Ingram, 2018; Kreiss \& McGregor, 2017). After a research article generated extensive news coverage of this industry-wide marketing practice, Facebook publicly announced it would cease the arrangement, instead "offering tools and advice" through a politics portal that provides "candidates information on how to get their message out and a way to get authorised to run ads on the platform" (Emerson, 2018; Jeffrey, 2018). In May 2019, the company also announced it would stop paying commissions to employees who sell political ads (Glazer \& Horowitz, 2019). Such a move may not have a major effect on sales, however, especially since the tech giant has already generated significant income from political advertising for the 2020 campaign (Evers-Hillstrom, 2019).

Under pressure from civil rights groups over discriminatory ad targeting practices in housing and other areas, Facebook has undergone an extensive civil rights audit, which has resulted in a number of internal policy changes, including some practices related to campaigns and elections. For example, the company announced in June 2019 that it had "strengthened its voter suppression policy" to prohibit "misrepresentations" about the voting process, as well as any "threats of violence related to voting". It has also committed to making further changes, including investments designed to prevent the use of the platform "to manipulate U.S. voters and elections" (Sandberg, 2019).

Google, Facebook, and Twitter have all established online archives to enable the public to find information on the political advertisements that run on their platforms. But these databases provide only a limited range of information. For example, Google's (2018) archive contains copies of all political ads run on the platform, shows the amount spent overall and on specific ads by a campaign, as well as age range, gender, area (state) and dates when an ad appeared, but does not share the actual "targeting criteria" used by political campaigns (Walker, 2018). Facebook's (n.d.-b) Ad Library describes itself as a "comprehensive, searchable collection of all ads currently running across Facebook Products". It claims to provide "data for all ads related to politics or to issues of national importance" that have run on its platform since May 2018 
(Sullivan, 2019). While the data include breakdowns on the age, gender, state where it ran, number of impressions and spending for the ad, no details are provided to explain how the ad was constructed, tested, and altered, or what digital ad targeting techniques were used. For example, Facebook (n.d.-a-e) permits US-based political campaigns to use its "Custom or Lookalike Audiences" ad-targeting product, but it does not report such use in its ad library. Though all of these new transparency systems and ad archives offer useful information, they also place a considerable burden on users. Many of these new measures are likely to be more valuable for watchdog organisations and journalists, who can use the information to track spending, identify emerging trends, and shed additional light on the process of digital political influence.

While these kinds of changes in platform policies and operations should help to mitigate some of the more egregious uses of social media by unscrupulous campaigns and other actors, they are not likely to alter in any major way the basic operations of today's political advertising practices. With each tech giant instituting its own set of internal ad policies, there are no clear industry-wide "rules-of-the-game" that apply to all participants in the digital ecosystem. Nor are there strong transparency or accountability systems in place to ensure that the policies are effective. Though platform companies may institute changes that appear to offer meaningful safeguards, other players in the highly complex big data marketing infrastructure may offer ways to circumvent these apparent restrictions. As a case in point, when Facebook (2018, n.d.-c) announced in the wake of the Cambridge Analytica scandal that it was "shutting down Partner Categories", the move provoked alarm inside the ad-tech industry that a set of powerful applications was being withdrawn (Villano, 2018). The product had enabled marketers to incorporate data provided by Facebook's selected partners, including Acxiom and Epsilon (Pathak, 2018). However, despite the policy change, Facebook still enables marketers to bring a tremendous amount of third-party data to Facebook for targeting (Popkin, 2019). Indeed, shortly after Facebook's announcement, LiveRamp offered assurances to its clients that no significant changes had been made, explaining that "while there's a lot happening in our industry, LiveRamp customers have nothing to fear" (Carranza, 2018).

The controversy generated by recent foreign interference in US elections has also fuelled a growing call to update US election laws. However, the current policy debate over regulation of political advertising continues to be waged within a very narrow framework, which needs to be revisited in light of current digital practices. Legislative proposals have been introduced in Congress that would strengthen the disclosure requirements for digital political ads regulated by the Federal Election Commission (FEC). For example, under the Honest Ads Act, digital media platforms would be required to provide information about each ad via a "public political file", including who purchased the ad, when it appeared, how much was spent, as well as "a description of the targeted audience". Campaigns would also be required to provide the same information for online political ads that are required for political advertising in other media. The proposed legislation currently has the support of Google, Facebook, Twitter and other leading companies (Ottenfeld, 2018, April 25). A more ambitious bill, the For the People Act is backed by the new Democratic majority in the House of Representatives, and includes similar disclosure requirements, along with a number of provisions aimed at reducing "the influence of big money in politics”. Though these bills are a long-overdue first step toward bringing transparency measures into the digital age, neither of them addresses the broad range of big data marketing and targeting practices that are already in widespread use across political campaigns. And it is doubtful whether either of these limited policy approaches stands a chance of passage in the near future. There is strong opposition to regulating political campaign and ad practices at the federal level, primarily because of what critics claim would be violations of the 
free speech principle of the US First Amendment (Brodey, 2019).

While the prospects for regulating political advertising appear dim at the present time, there is a strong bi-partisan move in Congress to pass federal privacy legislation that would regulate commercial uses of data, which could, in turn, affect the operations, tools, and techniques available for digital political campaigns. Google, Facebook, and other digital data companies have long opposed any comprehensive privacy legislation. But a number of recent events have combined to force the industry to change its strategy: the implementation of the EU General Data Protection Regulation (GDPR) and the passage of state privacy laws (especially in California); the seemingly never-ending news reports on Facebook's latest scandal; massive data breaches of personal information; accounts of how online marketers engage in discriminatory practices and promote hate speech; and the continued political fallout from "Russiagate". Even the leading tech companies are now pushing for privacy legislation, if only to reduce the growing political pressure they face from the states, the EU, and their critics (Slefo, 2019). Also fuelling the debate on privacy are growing concerns over digital media industry consolidation, which have triggered calls by political leaders as well as presidential candidates to "break up" Amazon and Facebook (Lecher, 2019). Numerous bills have been introduced in both houses of Congress, with some incorporating strong provisions for regulating both data use and marketing techniques. However, as the 2020 election cycle gets underway, the ultimate outcome of this flurry of legislative activity is still up in the air (Kerry, 2019).

\section{OPPORTUNITIES FOR INTERVENTION}

Given the uncertainty in the regulatory and self-regulatory environment, there is likely to be little or no restraint in the use of data-driven digital marketing practices in the upcoming US elections. Groups from across the political spectrum, including both campaigns and special interest groups will continue to engage in ferocious digital combat (Lennon, 2018). With the intense partisanship, especially fuelled by what is admittedly a high-stakes-for-democracy election (for all sides), as well as the current ease with which all of the available tools and methods are deployed, no company or campaign will voluntarily step away from the "digital arms race" that US elections have become. Given what is expected to be an extremely close race for the Electoral College that determines US presidential elections, 2020 is poised to see both parties use digital marketing techniques to identify and mobilise the handful of voters needed to "swing" a state one way or another (Schmidt, 2019).

Campaigns will have access to an unprecedented amount of personal data on every voter in the country, drawing from public sources as well as the growing commercial big data infrastructure. As a consequence, the next election cycle will be characterised by ubiquitous political targeting and messaging, fed continuously through multiple media outlets and communication devices.

At the same time, the concerns over continued threats of foreign election interference, along with the ongoing controversy triggered by the Cambridge Analytica/Facebook scandal, have reenergised campaign reform and privacy advocates and engaged the continuing interest of watchdog groups and journalists. This heightened attention on the role of digital technologies in the political process has created an unprecedented window of opportunity for civil society groups, foundations, educators, and other key stakeholders to push for broad public policy and structural changes. Such an effort would need to be multi-faceted, bringing together diverse organisations and issue groups, and taking advantage of current policy deliberations at both the federal and state levels. 
In other western democracies, governments and industry organisations have taken strong proactive measures to address the use of data-driven digital marketing techniques by political parties and candidates. For example, the Institute for Practitioners in Advertising (IPA), a leading UK advertising organisation, has called for a "moratorium on micro-targeted political advertising online". "In the absence of regulation", the IPA explained, "we believe this almost hidden form of political communication is vulnerable to abuse". Leading members of the UK advertising industry, including firms that work on political campaigns, have endorsed these recommendations (Oakes, 2018). The UK Information Commissioner's Office (ICO, 2018), which regulates privacy, conducted an investigation of recent digital political practices, and issued a report urging the government to "legislate at the earliest opportunity to introduce a statutory code of practice" addressing the "use of personal information in political campaigns" (Denham, 2018). In Canada, the Privacy Commissioner offered "guidance" to political parties in their use of data, including "Best Practices" for requiring consent when using personal information (Office of the Privacy Commissioner of Canada, 2019). The European Council (2019) adopted a similar set of policies requiring political parties to adhere to EU data protection rules.

We recognise that the United States has a unique regulatory and legal system, where First Amendment protections of free speech have limited regulation of political campaigns. However, the dangers that big data marketing operations pose to the integrity of the political process require a rethinking of policy approaches. A growing number of legal scholars have begun to question whether political uses of data-driven digital marketing should be afforded the same level of First Amendment protections as other forms of political speech (Burkell \& Regan, 2019; Calo, 2013; Rubinstein, 2014; Zarsky, 2019). "The strategies of microtargeting political ads", explain Jacquelyn Burkell and Priscilla Regan (2019), "are employed in the interests not of informing, or even persuading voters but in the interests of appealing to their non-rational biases as defined through algorithmic profiling".

Advocates and policymakers in the US should explore various legal and regulatory strategies, developing a broad policy agenda that encompasses data protection and privacy safeguards; robust transparency, reporting and accountability requirements; restrictions on certain digital advertising techniques; and limits on campaign spending. For example, disclosure requirements for digital media need to be much more comprehensive. At the very least, campaigns, platforms and networks should be required to disclose fully all the ad and data practices they used (e.g., cross-device tracking, lookalike modelling, geolocation, measurement, neuromarketing), as well as variations of ads delivered through dynamic creative optimisation and other similar AI applications. Some techniques - especially those that are inherently manipulative in nature should not be allowed in political campaigns. Greater attention will need to be paid to the uses of data and targeting techniques as well, articulating distinctions between those designed to promote robust participation, such as "Get Out the Vote" efforts, and those whose purpose is to discourage voters from exercising their rights at the ballot box. Limits should also be placed on the sources and amount of data collected on voters. Political parties, campaigns, and political action committees should not be allowed to gain unfettered access to consumer profile data, and voters should have the right to provide affirmative consent ("opt-in") before any of their information can be used for political purposes. Policymakers should be required to stay abreast of fast-moving innovations in the technology and marketing industries, identifying the uses and abuses of digital applications for political purposes, such as the way that WhatsApp was deployed during recent elections in Brazil for "computational propaganda" (Magenta, Gragnani, \& Souza, 2018). 
In addition to pushing for government policies, advocates should place pressure on the major technology industry players and political institutions, through grassroot campaigns, investigative journalism, litigation, and other measures. If we are to have any reform in the US, there must be multiple and continuous points of pressure. The two major political parties should be encouraged to adopt a proposed new best-practices code. Advocates should also consider adopting the model developed by civil rights groups and their allies in the US, who negotiated successfully with Google, Facebook and others to develop more responsible and accountable marketing and data practices (Peterson \& Marte, 2016). Similar efforts could focus on political data and ad practices. NGOs, academics, and other entities outside the US should also be encouraged to raise public concerns.

All of these efforts would help ensure that the US electoral process operates with integrity, protects privacy, and does not engage in discriminatory practices designed to diminish debate and undermine full participation. 


\section{REFERENCES}

2019 Reed Award winners. (2019, February 22). Campaigns \& Elections. Retrieved from https://www.campaignsandelections.com/campaign-insider/2019-reed-award-winners

AdVictory. (n.d.). Case study: Curating a data-driven CTV program. Retrieved from https://advictory.com/portfolio/rauner/

Agre, P. E., \& Rotenberg, M. (Eds). (1997). Technology and Privacy: The New Landscape. Cambridge, MA: The MIT Press.

American Association of American Political Consultants. (2019). 2019 Pollie Awards gallery. Retrieved from https://pollies.secure-platform.com/a/gallery?roundId=44

AT\&T. (n.d.). Head of political, DSP sales \& account management job. Lensa. Retrieved from https://lensa.com/head-of-political-dsp-sales--account-managementjobs/washington/jd/1444db7ddf6coa5d7568cb4032f3a4c7

Axelrod, T., Burke, M., \& Nam, R. (2019, February 25). Trump unleashing digital juggernaut ahead of 2020. The Hill. Retrieved from https://thehill.com/homenews/campaign/431181trump-unleashing-digital-juggernaut-ahead-of-2020

Axios. (2018, November 6). Political ad spending hits new record for 2018 midterm elections. Retrieved from https://www.axios.com/political-ad-spending-hits-new-record-for-2018midterm-elections-1541509814-28e24943-d68b-4f55-83ef-8b9d51a64fa9.html

Bashyakarla, V., Hankey, S., Macintyre, A., Rennó, R., \& Wright, G. (2019, March). Personal Data: Political Persuasion. Inside the Influence Industry. How it works. Berlin: Tactical Tech. Retrieved from https://cdn.ttc.io/s/tacticaltech.org/Personal-Data-Political-Persuasion-Howit-works.pdf

Baldwin-Philippi, J. (2017). The myths of data-driven campaigning. Political Communication, 34(4), 627-633. https://doi.org/10.1080/10584609.2017.1372999

Benes, R. (2018, June 20). Political advertisers will lean on programmatic during midterms. eMarketer. Retrieved from https://content-na1.emarketer.com/political-advertisers-will-leanon-programmatic-during-midterms

Bennett, C. J. (2008) The Privacy Advocates: Resisting the Spread of Surveillance. Cambridge, MA: The MIT Press.

Bennett, C. J. (2016). Voter databases, micro-targeting, and data protection law: Can political parties campaign in Europe as they do in North America? International Data Privacy Law, 6(4), 261-275. https://doi.org/10.1093/idpl/ipwo21 Retrieved from https://papers.ssrn.com/sol3/papers.cfm?abstract_id=2776299

Blommaert, J. (2019, January 22). Alexandria Ocasio-Cortez: The next level of political digital culture. Diggit Magazine. Retrieved from https://medium.com/@diggitmagazine/alexandriaocasio-cortez-the-next-level-of-political-digital-culture-e43b45518e86.

Bodo, B., Helberger, N., \& de Vreese, C. H. (2017). Political micro-targeting: a Manchurian candidate or just a dark horse? Towards the next generation of political micro-targeting research. Internet Policy Review, 6(4). https://doi.org/10.14763/2017.4.776 
Boynton, P. (2018, August 27). YouTube Director Mix: Create impactful video ads with less resources. Retrieved from Instapage Blog: https://instapage.com/blog/youtube-director-mix

Brodey, S. (2019, May 10). Sen. Lindsey Graham takes heat from conservatives for backing John McCain's election meddling bill. The Daily Beast. Retrieved from https://www.thedailybeast.com/lindsey-graham-takes-heatfrom-conservatives-for-backing-mccains-election-meddling-bill

Burkell, J., \& Regan, P.M. (2019, April). Voter preferences, voter manipulation, voter analytics: Policy options for less surveillance and more autonomy. Workshop on Data Driven Elections, Victoria.

California Clean Money Campaign. (2019, October 9). Gov. Newsom signs landmark disclosure bills: Petition DISCLOSE Act and Text Message DISCLOSE Act. California Clean Money Action Fund. Retrieved from http://www.yesfairelections.org/newslink/ccmc_2019-10-09.php

Calo, M. R. (2013). Digital market manipulation. George Washington Law Review, 82(4), 995-1051. Retrieved from https://www.gwlr.org/calo/

Carranza, M. (2018, July 17). How to use first $\square$ and third-party data on Facebook [Blog post]. Retrieved from LiveRamp blog: https://liveramp.com/blog/facebook-integration/.

Chester J., \& Montgomery, K. C. (2017). The role of digital marketing in political campaigns. Internet Policy Review, 6(4). https://doi.org/10.14763/2017.4.773

Chester J., \& Montgomery, K. C. (2018). The influence industry: Contemporary digital politics in the United States [Report]. Berlin: Tactical Tech. Retrieved from

https://ourdataourselves.tacticaltech.org/media/ttc-influence-industry-usa.pdf.

Chester, J. (2007). Digital Destiny: New Media and the Future of Democracy. New York: The New Press.

Clancy. M. (2018, August 17). A4 adds Inscape's Vizio TV data to measurement mix. Rapid TV News. Retrieved from https://www.rapidtvnews.com/2018081753198/a4-adds-inscape-svizio-tv-data-to-measurement-mix.html\#axzz5kdEAVLYs.

Denham, E. (2018, November 6). Blog: Information Commissioner's report brings the ICO's investigation into the use of data analytics in political campaigns up to date. ICO. Retrieved from https://ico.org.uk/about-the-ico/news-and-events/blog-information-commissioner-sreport-brings-the-ico-s-investigation-into-the-use-of-data-analytics-in-politicalcampaigns-up-to-date.

Dischler, J. (2018, July 10). Putting machine learning into the hands of every advertiser. Google Blog. Retrieved from https://www.blog.google/technology/ads/machine-learning-handsadvertisers/.

Dorsey, J. (2019, October 30). We've made the decision to stop all political advertising on Twitter globally. We believe political message reach should be earned, not bought. Why? A few reasons.... [Tweet]. Retrieved from https://twitter.com/jack/status/1189634360472829952.

Echelon Insights. (2019). 2019 Reed awards winner: Innovation in Polling. Retrieved from https://echeloninsights.com/news/theanalyticsjumpstart/ 
Emerson, S. (2018, August 15). How Facebook and Google win by embedding in political campaigns. Vice. Retrieved from https://www.vice.com/en_us/article/ne5k8z/how-facebookand-google-win-by-embedding-in-political-campaigns

European Council. (2019, March 3). EP elections: EU adopts new rules to prevent misuse of personal data by European political parties. Retrieved from

https://www.consilium.europa.eu/en/press/press-

releases/2019/o3/19/ep-elections-eu-adopts-

new-rules-to-prevent-misuse-of-personal-data-by-european-political-parties/

Evers-Hillstrom, K. (2019). Democratic presidential hopefuls flock to Facebook for campaign cash. Retrieved from https://www.opensecrets.org/news/2019/o2/democratic-presidentialhopefuls-facebook-ads/

Facebook. (2018, March 28) Shutting down partner categories. Facebook Newsroom. Retrieved from https://newsroom.fb.com/news/h/shutting-down-partner-categories/

Facebook. (2019, March 27). Boost liquidity and work smarter with machine learning. Facebook Business. Retrieved from https://www.facebook.com/business/news/insights/boost-liquidityand-work-smarter-with-machine-learning

Facebook. (n.d.-a). Ads about social issues, elections or politics. Retrieved from https://www.facebook.com/business/help/1838453822893854

Facebook. (n.d.-b). Facebook ad library. Retrieved from

https://www.facebook.com/ads/library/?active_status=all\&ad_type=political_and_issue_ads \&country=US

Facebook. (n.d.-c). Upcoming changes. Facebook Business. Retrieved from

https://www.facebook.com/business/m/one-sheeters/improving-

accountability-and-updates-for-facebook-targeting

Filloux, F. (2019, June 2). Trump's digital campaign for 2020 is already soaring. Monday Note. Retrieved from https://mondaynote.com/trumps-digital-campaign-for-2020-is-alreadysoaring-doo75bee8e89

Fitzpatrick, R. (2018, March 1). Resonate wins Reed Award for "best application of artificial intelligence or machine learning" [Blog post]. Resonate Blog. Retrieved from

https://www.resonate.com/blog/resonate-wins-reed-award-for-bestapplication-of-artificial-intelligence-or-machine-learning/

Friedman, W. (2018, June 19). 2020 political ad spend could hit \$10 billion, digital share expected to double. MediaPost. Retrieved from

https://www.mediapost.com/publications/article/337226/2020-political-ad-spend-could-hit-1 o-billion-dig.html

FWIW: The platform self-regulation dumpster fire. (2019, November 22). ACRONYM. Retrieved from https://www.anotheracronym.org/newsletter/fwiw-the-platform-self-regulationdumpster-fire/.

Garrahan, A. (2018, September 4). California's new "Social Media DISCLOSE Act” regulates social media companies, search engines, other online advertising outlets, and political 
advertisers. Inside Political Law. Retrieved from

https://www.insidepoliticallaw.com/2018/o9/04/californias-new-social-media-disclose-act-reg ulates-social-media-companies-search-engines-online-advertising-outlets-political-advertisers/

Glazer, E. \& Horwitz, J. (2019, May 23). Facebook curbs incentives to sell political ads ahead of 2020 election. Wall Street Journal. Retrieved from https://www.wsj.com/articles/facebookends-commissions-for-political-ad-sales-11558603803

Google. (2018). Transparency report: Political advertising in the United States. Retrieved from: https://transparencyreport.google.com/political-ads/region/US

Google. (n.d.-a). About responsive search ads (beta). Google Ads Help. Retrieved from https://support.google.com/google-ads/answer/7684791

Google. (n.d.-b). About smart display campaigns. Retrieved from https://support.google.com/google-ads/answer/7020281

Google (n.d.-c). Vogon. Retrieved from https://opensource.google.com/projects/vogon

Gorton, W. A. (2016). Manipulating citizens: How political campaigns' use of behavioural social science harms democracy. New Political Science 38(1), 61-80.

https://doi.org/10.1080/07393148.2015.1125119

Gray, C. M., Kou, Y., Battles, B., Hoggatt, J., \& Toombs, A. L. (2018). The Dark (Patterns) Side of UX Design. Proceedings of the 2018 CHI Conference on Human Factors in Computing Systems - CHI 18. https://doi.org/10.1145/3173574.3174108

Green, J. \& Issenberg, S. (2016, October 27). Inside the Trump bunker, with days to go. Bloomberg Businessweek. Retrieved from https://www.bloomberg.com/news/articles/201610-27/inside-the-trump-bunker-with-12-days-to-go

Griner, D. (2019, June 25). Here's every Grand Prix winner from the 2019 Cannes Lions. Adweek. Retrieved from https://www.adweek.com/creativity/heres-every-grand-prix-winnerfrom-the-2019-cannes-lions/

Howard, P. N., Woolley, S., \& Calo, R. (2018). Algorithms, bots, and political communication in the US 2016 election: The challenge of automated political communication for election law and administration. Journal of Information Technology \& Politics, 15(2), 81-93.

https://doi.org/10.1080/19331681.2018.1448735

IAB. (n.d.-a). The new TV. Retrieved from https://video-guide.iab.com/new-tv

IAB Europe. (2019, June 5). Winners announced for the MIXX Awards Europe 2019 [Blog post]. IAB Europe Blog. Retrieved from https://iabeurope.eu/all-news/winners-announced-for-themixx-awards-europe-2019/

ICO. (2018). Call for views: Code of practice for the use of personal information in political campaigns. Retrieved from https://ico.org.uk/about-the-ico/ico-and-stakeholderconsultations/call-for-views-code-of-practice-for-the-use-of-personalinformation-in-political-campaigns/

Ingram, D. (2018, September 20). Facebook to scale back 'embeds' for political campaigns. NBC News. Retrieved from https://www.nbcnews.com/tech/tech-news/facebook-scale-back- 
embeds-political-campaigns-n911701

Inscape. (n.d.). Solutions. Retrieved from https://www.inscape.tv/solutions

Isaac, M. (2019, November 22). Why everyone is angry at Facebook over its political ads policy. The New York Times. Retrieved from

https://www.nytimes.com/2019/11/22/technology/campaigns-pressure-facebook-political-ads. html

Jeffrey, C. (2018, September 21). Facebook to stop sending "embeds" into political campaigns. TechSpot. Retrieved from https://www.techspot.com/news/76563-facebook-stop-sendingembeds-political-campaigns.html

Kafka, P. (2019, December 10). Facebook's political ad problem, explained by an expert. Vox. Retrieved from https://www.vox.com/recode/2019/12/10/20996869/facebook-political-adstargeting-alex-stamos-interview-open-sourced

Kantar. (2019, June 26). Kantar forecasts \$6 billion in political ad spending for 2019-2020 election cycle [Press release]. Retrieved from

https://www.kantarmedia.com/us/newsroom/press-releases/kantar-forecasts6-billion-in-politi cal-ad-spending-for-2019-2020-election-cycle

Karpf, D. (2016, October 31). Preparing for the campaign tech bullshit season. Civicist. Retrieved from https://civichall.org/civicist/preparing-campaign-tech-bullshit-season/

Kerry, C. F. (2019, March 8). Breaking down proposals for privacy legislation: How do they regulate? [Report]. Washington, DC: The Brookings Institution. Retrieved from https://www.brookings.edu/research/breaking-down-proposals-for-privacylegislation-how-do-they-regulate/

Kim, Y. M., Hsu, J., Neiman, D., Kou, C., Bankston, L., Kim, S. Y., Heinrich, R., Baragwanath, R., \& Raskutti, G. (2018). The stealth media? Groups and targets behind divisive issue campaigns on Facebook. Political Communication, 35(4), 515-541.

https://doi.org/10.1080/10584609.2018.1476425

Kreiss, D. (2016). Prototype Politics: Technology-intensive Campaigning and the Data of Democracy. New York: Oxford University Press.

https://doi.org/10.1093/acprof:oso/9780199350247.001.0001

Kreiss, D., \& Howard, P. N. (2010). New challenges to political privacy: Lessons from the first US presidential race in the web 2.0 era. International Journal of Communication, 4, 1032-1050. Retrieved from http://ijoc.org/index.php/ijoc/article/viewFile/870/473

Kreiss, D., \& McGregor, S. C. (2017). Technology firms shape political communication: The work of Microsoft, Facebook, Twitter, and Google with campaigns during the 2016 US presidential cycle, Political Communication, 35(2), 155-177.

https://doi.org/10.1080/10584609.2017.1364814

Lafayette, J. (2019, June 27). Elections to generate \$6B in ad spending: Kantar. Broadcasting \& Cable. Retrieved from https://www.broadcastingcable.com/news/elections-to-generate-6b-inad-spending-kantar. 
Lecher, C. (2019, March 8). Elizabeth Warren says she wants to break up Amazon, Google, and Facebook. The Verge. Retrieved from

https://www.theverge.com/2019/3/8/18256032/elizabeth-warren-antitrust-google-amazon-fac ebook-break-up

Lennon, W. (2018, October 9). An introduction to the Koch digital media network. Open Secrets. Retrieved from https://www.opensecrets.org/news/2018/10/intro-to-koch-brothersdigital/

Lerner, R. (2019, September 24). OTT advertising will be a clear winner in the 2020 elections. $T V[R] E V$. Retrieved from https://tvrev.com/ott-advertising-will-be-a-clear-winner-in-the2020-elections/

Loredo, A. (2016, March). Centro automates political ad-buying at scale on brand-safe news and information sites. Centro Blog. Retrieved from https://www.centro.net/blog/centro-brandexchange-political-ads/

Lynch, J. (2018, November 15). Advertisers spent \$5.25 billion on the midterm election, 17\% more than in 2016." Adweek. Retrieved from

https://www.kantarmedia.com/us/newsroom/km-inthenews/advertisers-spent-5-25-billion-on -the-midterm-election

McAfee, J. (2019, January 8). Inscape on the power of automatic content recognition and trends in TV consumption. Adelphic Blog. Retrieved from https://www.adelphic.com/inscape-on-thepower-of-automatic-content-recognition-and-trends-in-tv-consumption/

McCullough, S. C. (2016, April 3). When it comes to political programmatic advertising, the creative has to be emotionally charged. Adweek. Retrieved from

https://www.adweek.com/brand-marketing/when-it-comespolitical-programmatic-advertising-creative-has-be-emotionally-charged-170559/

Magenta, M., Gragnani, J., \& Souza, F. (2018, October 24). How WhatsApp is being abused in Brazil's elections. BBC News. Retrieved from https://www.bbc.com/news/technology-45956557

Meuse, K. (2018, September 5). Put the wow factor in your campaigns with dynamic creative. Sizmek Blog. Retrieved from https://www.sizmek.com/blog/put-the-wow-factor-in-yourcampaigns-with-dynamic-creative/.

Miller, S. J. (2018, November 23). Trade group successfully targeted voters on Waze ahead of midterms. Campaigns \& Elections. Retrieved from

https://www.campaignsandelections.com/campaign-insider/trade-group-successfully-targetedvoters-on-waze-ahead-of-midterms.

Mindshare. (2017). POV: YouTube Director Mix. Retrieved from https://www.mindshareworld.com/news/pov-youtube-director-mix.

MMA. (2019). Smarties X. Retrieved from https://www.mmaglobal.com/smarties2019.

Montgomery, K. C. (2007). Generation Digital: Politics, Commerce, and Childhood in the Age of the Internet. Cambridge, MA: The MIT Press.

Montgomery, K. C. (2015). Youth and surveillance in the Facebook era: Policy interventions and 
social implications. Telecommunications Policy, 39(3), 771-786.

https://doi.org/10.1016/j.telpol.2014.12.006.

Montgomery, K. C., \& Chester, J. (2009). Interactive food and beverage marketing: Targeting adolescents in the digital age. Journal of Adolescent Health, 45(3).

https://doi.org/10.1016/j.jadohealth.2009.04.006

Montgomery, K. C., Chester, J., Grier, S. A., \& Dorfman, L. (2012). The new threat of digital marketing. Pediatric Clinics of North America, 59(3), 659-675.

https://doi.org/10.1016/j.pcl.2012.03.022

Montgomery, K. C., Chester, J., \& Kopp, K. (2017). Health wearable devices in the big data era: Ensuring privacy, security, and consumer protection [Report]. Washington, DC: Center for Digital Democracy. Retrieved from

https://www.democraticmedia.org/sites/default/files/field/public/2016/aucdd_wearablesrepo rt_final121516.pdf

Mothership Strategies. (2018). Case study: Doug Jones for senate advertising. Retrieved from https://mothershipstrategies.com/doug-jones-digital-advertising-mothership/

Nissenbaum, H. (2009). Privacy in Context: Technology, Policy, and the Integrity of Social Life. Redwood City: Stanford Law Books.

Oakes, O. (2018, April 20). IPA calls for suspension of micro-targeted political ads. Campaign. Retrieved from https://www.campaignlive.co.uk/article/ipa-calls-suspension-micro-targetedpolitical-ads/1462598

Office of the Privacy Commissioner of Canada. (2019, April 1). Guidance for federal political parties on protecting personal information. Retrieved from https://www.priv.gc.ca/en/privacytopics/collecting-personal-information/gd_pp_201904

O’Keefe, P. (2019, March 31). Relational digital organizing-the next political campaign battleground. Medium. Retrieved from https://medium.com/political-moneyball/relationaldigital-organizing-the-next-political-campaign-battleground-48ab1f7c2eef

O’Reilly, M. (2018, June 1). FCC regulatory free arena [Blog post]. Retrieved from FCC Blog: https://www.fcc.gov/news-events/blog/2018/o6/o1/fcc-regulatory-free-arena

Ottenfeld, E. (2018, April 25). Who supports the Honest Ads Act? Some of the country's largest tech firms. Issue One. Retrieved from https://www.issueone.org/who-supports-the-honestads-act/

Pathak, S. (2018, March 30). How Facebook's shutdown of third-party data affects advertisers. Digiday. Retrieved from https://digiday.com/marketing/facebooks-shutdown-third-partydata-affects-brands/.

Perrin, N. (2019, July 19). Political ad spend to reach $\$ 6$ billion for 2020 election. eMarketer. Retrieved from https://www.emarketer.com/content/political-ad-spend-to-reach-6-billionfor-2020-election

Peterson, A. \& Marte, J. (2016, May 11). Google to ban payday loan advertisements. Washington Post. Retrieved from https://www.washingtonpost.com/news/the- 
switch/wp/2016/o5/11/google-to-ban-payday-loanadvertisements/?utm_term=.6fb6oc626bo5

Peterson, T. (2017, October 30). Facebook's dynamic creative can generate up to 6,250 versions of an ad. Marketing Land. Retrieved from https://marketingland.com/facebooks-dynamiccreative-option-can-automatically-produce-6250-versions-ad-227250

Popkin, D. (2019, February 15). Optimizing Facebook campaigns with third-party data [Blog post]. Retrieved from LiveRamp Blog: https://liveramp.com/blog/facebook-campaigns/

Revolution Marketing. (n.d.). Creative. Retrieved from

https://revolutionmessaging.com/services/creative/

Rapp, L. (2018, September 25). Announcing LiveRamp AbiliTec [Blog post]. Retrieved from LiveRamp Blog: https://liveramp.com/blog/abilitec/

Rosenberg, M., Confessore, N., \& Cadwalladr. C. (2018, March 17). How Trump consultants exploited the Facebook data of millions. The New York Times. Retrieved from https://www.nytimes.com/2018/o3/17/us/politics/cambridge-analytica-trump-campaign.html

Rubinstein, I. (2014). Voter privacy in the age of big data. Wisconsin Law Review, 2014(5), 861-936. Retrieved from http://wisconsinlawreview.org/wp-content/uploads/2015/o2/1-Rubinstein-Final-Online.pdf

Sandberg, S. (2019, June 30). A second update on our civil rights audit. Facebook Newsroom. Retrieved from https://newsroom.fb.com/news/2019/o6/second-update-civil-rights-audit/

Schiff, A. (2018, February 14). Ericsson Emodo beefs up its ad tech chops with Placecast acquisition. AdExchanger. Retrieved from https://adexchanger.com/mobile/ericsson-emodobeefs-ad-tech-chops-placecast-acquisition/

Schmidt, S. (2019, July 11). A shadow digital campaign may prove decisive in 2020-and Donald Trump has a clear advantage. AlterNet. Retrieved from https://www.alternet.org/2019/o7/ashadow-digital-campaign-may-prove-decisive-in-2020-and-donald-trump-has-a-clearadvantage/

Schuster, J. (2015, October 7). Political campaigns: The art and science of reaching voters [Blog post]. Retrieved from LiveRamp Blog: https://liveramp.com/blog/political-campaigns-the-artand-science-of-reaching-voters/

Schwartz, P. M., \& Solove, D.J. (2011). The PII problem: Privacy and a new concept of personally identifiable information." New York University Law Review, 86, 1814-1894. Retrieved from http://scholarship.law.berkeley.edu/cgi/viewcontent.cgi?article=2638\&context=facpubs

Shah, A. (2019, March 14). Why political parties should focus on programmatic advertising this elections [Blog post]. AdAge India. Retrieved from

http://www.adageindia.in/blogs-columnists/guest-columnists/why-political-parties-should-foc us-on-programmatic-advertising-this-elections/articleshow/68402528.cms

Skyhook. (n.d.). Geospatial insights. Retrieved from https://www.skyhook.com/geospatialinsights/

Slefo, G.P. (2019, April 8). Ad industry groups band together to influence Congress on data 
privacy. AdAge. Retrieved from https://adage.com/article/digital/ad-industry-groups-bandtogether-influence-congress-data-privacy/2162976.

Sluis, S. (2018, June 27). DoubleClick no more! Google renames its ad stack. AdExchanger. Retrieved from https://adexchanger.com/platforms/doubleclick-no-more-google-renames-itsad-stack/.

Spencer, S. (2019, November 20). An update on our political ads policy [Blog post]. Retrieved from Google Blog: https://www.blog.google/technology/ads/update-our-political-ads-policy/.

Sullivan, M. (2019, March 28). Facebook expands ad transparency beyond politics: Here's what's new. Fast Company. Retrieved from https://www.fastcompany.com/90326809/facebook-expands-archive-ad-library-for-political-a ds-heres-whats-new

Susser, D., Roessler, B., \& Nissenbaum, H. F. (2019). Online manipulation: Hidden influences in a digital world. Georgetown Law Technology Review, 4(1), 1-45. Retrieved from https://georgetownlawtechreview.org/online-manipulation-hidden-influencesin-a-digital-world/GLTR-01-2020/

TransUnion (2019, May 15). TransUnion strengthens digital marketing solutions with agreement to acquire TruSignal. Retrieved from https://newsroom.transunion.com/transunion-strengthens-digital-marketing-solutions-with-a greement-to-acquire-trusignal/

Tru Optik. (2019, June 17). Tru Optik launches political data cloud for connected TV and streaming audio advertising. Retrieved from https://www.truoptik.com/tru-optik-launchespolitical-data-cloud-for-connected-tv-and-streaming-audio-advertising.php

Tufekci, Z. (2014). Engineering the public: Big data, surveillance and computational politics. First Monday, 19(7). https://doi.org/10.5210/fm.v19i7.4901/

Villano, L. (2018, July 19). The loss of Facebook Partner categories: How marketers can cope. MediaPost. Retrieved from https://www.mediapost.com/publications/article/322380/theloss-of-facebook-partner-categories-how-marke.html

Walker, K. (2018, May 4). Supporting election integrity through greater advertising transparency [Blog post]. Retrieved from Google Blog: https://www.blog.google/outreachinitiatives/public-policy/supporting-election-integrity-through-greater-advertisingtransparency/

Weissbrot, A. (2019, April 5). Magna predicts US OTT ad revenues will double by 2020. AdExchanger. Retrieved from https://adexchanger.com/tv-2/magna-predicts-us-ott-adrevenues-will-double-by-2020/

Weissbrot, A. (2019, October 22). Roku to acquire Dataxu for $\$ 150$ million. AdExchanger. Retrieved from https://adexchanger.com/digital-tv/roku-to-acquire-dataxu-for-150-million/

Weissbrot, A. (2019, April 10). Waze makes programmatic inventory available in dv360. AdExchanger. Retrieved from https://adexchanger.com/platforms/waze-makesprogrammatic-inventory-available-in-dv36o/ 
Williams, R. (2019, October 8). IPG launches martech platform Kinesso to marry Acxiom data with ad campaigns. Marketing Dive. Retrieved from

https://www.marketingdive.com/news/ipg-

launches-martech-platform-kinesso-to-marry-acxiom-data-with-ad-campaign/564527/

WPA Intelligence. (2019). WPAi wins big at 2019 Reed Awards. Retrieved from http://wpaintel.com/2019reedawards/

Xandr. (n.d.). Political advertising. Retrieved from https://www.xandr.com/legal/politicaladvertising/

Zarsky, T.Z. (2019). Privacy and manipulation in the digital age. Theoretical Inquiries in Law, 2O(1), 157-188. https://doi.org/10.1515/til-2019-0oo6

Zuboff, S. (2019). The Age of Surveillance Capitalism: The Fight for a Human Future at the New Frontier of Power. New York: Public Affairs.

\section{FOOTNOTES}

1. We have relied on a diverse set of primary and secondary materials for our research, including trade journals, research reports, and other industry documents, as well as personal participation in, and proceedings from conferences focused on digital technologies and politics. 